Fernando Alegría

\title{
Sobre el Encuentro de Escritores en Concepción
}

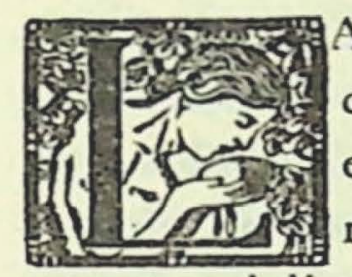

A EVALUACION crítica e histórica del Primer Encuentro de Escritores Chilenos, realizado en el mes de enero de 1958 en la Universidad de Concepción, es tarea que habrá de realizarse con objetiva minuciosidad por especialistas y estudiosos de nuestra literatura. Creo que su importancia irá creciendo con el tiempo y que el conjunto de trabajos allí leídos llegará a constituirse en fuente de referencia indispensable para la justa comprensión de los aportes que ha llevado a la cultura chilena la llamada generación de 1938. Hago hincapié en esta delimitación. A este Encuentro, en realidad, se invitó solamente a un grupo que se consideró representativo de una generación. Ausentes quedaron escritores de la misma generación y de mucho mérito, y otros de prestigio indiscutible tanto de la generación de 1920 como de la de 1930. Se invitó, por otra parte, a algunos escritores muy jóvenes, de labor incipiente, con el propósito obvio de que contribuyeran a completar un cuadro vivo, polémico, de un momento en la literatura chilena contemporánea.

No puede afirmarse que en este Encuentro de Escritores se haya debatido un problema central. En su convocatoria el Rector de la Universidad de Concepción, don David Stitchkin Branover, expresó: 
"El Encuentro de Escritores no tiene carácter de congreso, por cuanto no se ha propuesto un temario ni se exigen ponencias ni conclusiones. Solamente se debatirán en mesa redonda los temas que libremente han ofrecido los invitados sobre la especie literaria que cada uno de ellos practica". No obstante la amplitud de este planteamiento inicial, desde las primeras reuniones se pudo ver que ciertos problemas polarizaban la atención de los escritores y que ciertos criterios básicos les separaban en bandos más o menos identificables.

Acaso la preocupación más inmediata, más honda e intensamente sentida, fue la de traducir dialécticamente nuestra conciencia de pertenecer a una generación literaria; así como la impresión más generalizada fue de que, por pertenecer a tal generación, podíamos reunirnos, discutir, analizar y definir posiciones, sin llegar jamás al rompimiento que nuestras divergencias políticas, religiosas o de otra índole hubiesen podido provocar. Estos dos hechos son de una significación esencial. Si llegamos a la Universidad de Concepción conociéndonos mal o no conociéndonos, distanciados o divididos por innumerables circunstancias, en el transcurso del Encuentro descubrimos una condición -creativa y dinámica- que nos unió firmemente y nos obligó, luego, a identificarla y definirla. Sentimos que en el plano de la creación literaria asumíamos una responsabilidad común en función de la cultura chilena y que por encima de divergencias doctrinarias nos movía la necesidad de aquilatar los fundamentos de esta cultura para lograr, a la postre, reconocernos y definirnos a nosotros mismos.

Sabiéndonos parte de una nueva generación se nos impuso la faena de analizar desde un punto de vista crítico la herencia que nos legaron nuestros mayores y de señalar la orientación de nuestras innovaciones. Tal fue la misión cumplida especialmente por Braulio Arenas, Volodia Teitelboin, Luis Oyarzún, Fernando Debesa, LuisAlberto Heiremans, Nicomedes Guzmán, Nicanor Parra y Mario Espinoza. La Resolución de medio siglo, que leí en la reunión inaugural, fue asimismo una respuesta a semejante demanda. Desde los primeros debates pudo advertirse, por otra parte, que esta labor de revi- 
sión histórica no era sino el punto de partida para afrontar problemas de significación más particular y decisiva en el examen de nuestra labor de escritores. En síntesis, esos problemas fueron los siguientes:

\section{1) El concepto de generación}

Las generaciones no se definen ni se identifican con un criterio estrictamente cronológico, sino en la comunidad de sus propósitos y de su destino; lo sabíamos todos, pero debimos escuchar atentamente a quienes lo repitieron porque al repetirlo contribuían a iluminar el hecho que, en el fondo, no podía dejar de apasionarnos: constituimos una generación porque en la multiplicidad de nuestras divergencias se encierran rasgos y actitudes que, en conjunto, forman un estilo de vida y de creación. Somos escritores comprometidos: los católicos, los marxistas, los liberales y, particularmente, los que rehúyen con pasión todo compromiso. Unos se hallan comprometidos en una declaración de fe - fe genuina, y por genuina respetable-, otros están comprometidos en la defensa de su falta de fe; y todos nos comprometemos -hasta las entrañas- en la creación responsable, digna, libre, de la obra de arte. Unos aparecen preocupados por su salvación personal y por la salvación de la humanidad, otros, por expresar su desesperación, su desventura y el presentimiento de su perdición. Nuestra tarea es la de una generación de escritores que acepta vivir en una época de crisis, que se enfrenta a ella y se salva o se pierde libremente. Escuchemos algunas opiniones vertidas en el Encuentro sobre este problema:

Armando Cassigoli: "Toda literatura debe ser comprometida y siempre lo ha sido. No existe otra posibilidad".

Herbert Müller: A la pregunta ¿qué piensa de la literatura comprometida? respondió: "Considero que no es literatura. Llamémosle panfleto, afiche, propaganda, cualquiera cosa menos literatura. Pero sí estimo que todo artista tiene un compromiso: dejar constancia de su libre y particular vișión de las cosas". 
José Manuel Vergara: "Existen dos clases de compromiso para un artista (ya no sólo para un literato, para un artista). Compromiso primero: adopta una actitud de amor o de odio hacia el ser. El otro tipo de compromiso se verifica mediante un libre movimiento del artista que, como ser humano, se comprometa a salvarse y a salvar mediante una jerarquía de valores que él cree la mejor".

Como se ve, no hay acuerdo ni en el sentido de la crisis que nos condiciona ni en el forma en que debemos afrontarla. No nos une ninguna modalidad artística en particular. Pero sí queremos reconocer una raíz espiritual que asciende desde el fondo de nuestra nacionalidad en gestación y que, al ser reconocida, nos une imponiéndonos el deber de combatir toda expresión seudoliteraria, interesada en disimular sus evasiones, su irresponsabilidad, y su ineficacia con pintorescos llamados a adormecer la conciencia en el goce de los aspectos superficiales de la realidad. De esta actitud nuestra, esencialmente analítica y constructiva, surgió un debate sobre la poesía, la crítica y la novela que, acaso, represente la contribución más interesante de este Encuentro de Escritores.

\section{2) La legitimidad de la crítica oficial chilena}

La crítica literaria en Chile fue objeto de una discusión general en la primera reunión del Encuentro. En mi trabajo manifesté que, si bien es cierto que los críticos de la pasada generación contribuyeron a orientar el desarrollo de la novela regionalista, no es menos cierto que abandonaron a la poesía y, en algunos casos, la obstruyeron con su oposición abierta y obstinada. Su concepción de la crítica, básicamente impresionista, les indujo a alejarse de las estrictas disciplinas que imponen la investigación literaria de alta escuela y la evaluación de la obra de arte con criterio estrictamente estético. Mario Osses, al variar la perspectiva histórica del debate inicial, enfocó la producción crítica de los escritores de nuestra generación y debió reconocerse que en el terreno del ensayo, de la monografía, así como de la reseña crítica breve, puede notarse hoy una voluntad de devol- 
ver a la crítica chilena la objetividad, la solidez bibliográfica, la profundidad ideológica que le faltaron en años pasados.

\section{3) La poesia chilena}

El debate sobre la poesía chilena no constituyó, como pudiera pensarse, un duelo entre dos generaciones. Quienes así lo entendieron, erraron. Es verdad que en el proceso de revisión crítica a que se sometió a la poesía chilena de los últimos treinta años, se notaron dos posiciones claramente definidas, representada una por $\mathrm{H}$. Díaz Casanueva, poeta de la generación de 1920, y la otra, por Miguel Arteche, poeta de la generación más joven. Ambas posiciones, sin embargo, fueron cuidadosamente fundamentadas hasta el punto de permitir una integración final tanto en el plano estético como en el plano histórico. Aún en las más acerbas críticas de Arteche hay el reconocimiento de una etapa de creación poética que demanda ser superada, no destruida - lo que sería pueril empeño-, y cuyos más altos aportes no pierden del todo su vigencia. Efraín Barquero, poeta de la misma generación de Arteche, fue explícito a este respecto:

"Hombres como Neruda, Huidobro, de Rokha, Humberto Díaz y Juvencio Valle, han embellecido el oficio poético. No se trata de ponerse en contra de ellos, sino de aprovechar todos sus hallazgos".

La posición de Miguel Arteche puede resumirse extractando algunas citas de su ponencia titulada "Notas para la vieja y la nueva poesía chilena":

"Es muy posible que mi promoción pase a la historia de la poesía chilena como un núcleo que, al enfrentarse al fenómeno poético, estuvo provisto no sólo de una seriedad ante el oficio, ante el rigor idiomático (que no se explica con teorías o con artes poéticas, sino que se demuestra por un hecho concreto: el poema), también actuó con la conciencia de que la estructura, el control y la presión a que debe estar sometida la poesía son tan importantes para ésta como el ejercicio que el pensamiento realiza en lo más profundo de la com- 
posición poética... Ni el verso libre ni el tradicional significan nada sin una actitud espiritual, interna, bien precisa y concreta.

"No hay falta de audacia en los nuevos poetas chilenos por el hecho de que, apoyándose en elementos unitarios y rítmicos, e incluso, empleando formas tradicionales, hayan vuelto a cantar cosas que no tuvieron crédito hace treinta o más años. Lo que han hecho y lo que hacen ahora, no es menos revolucionario que lo que hicieron los poetas mayores de Chile. No han tratado de hacerse más claros por prejuicios políticos, y menos han creído que dar cuenta de los americanos es escribir sobre realidades físicas de América porque, para hacerlo, hay que dar cuenta antes que nada de una problemática espiritual (de cualquier naturaleza que sea), y luego, pero en muchísimo menor grado, de una actitud ante los hechos físicos de nuestro continente. Los poetas jóvenes conocemos algo más que nuestro mundo chileno. No pretendemos haber dado siempre en el blanco; pero tratamos de alcanzar el rigor de la palabra poética, la cual vive en el océano idiomático, nadando en un idioma que, como el castellano que se habla y escribe en América (por su carácter provisional), obliga al escritor, y con mucho más razón al poeta, a mantenerse con una conciencia lúcida y alerta".

La crítica de Arteche a la generación de Neruda, Huidobro, de Rokha, Rosamel del Valle y Díaz Casanueva, se sintetiza en estas palabras:

"Los viejos poetas hablan -es su truco- con la naturalidad del que conversa claramente sobre todas las cosas; sorprenden al lector hablándole con la misma sencillez con que se dicen o se refieren todas las historias triviales; pero escamotean la historia: ponen en vez de algo que se desenvuelve según las reglas clásicas de la lógica, incoherencias, motivos absurdos. De esta manera, lo fantástico se torna más fantástico; lo "irreal" participa, fraudulentamente, de. lo real; la "poesía" de la prosa; la "imagen" de la palabra. Y no es cuestión de simple ignorancia de la gramática: son el mal gusto y la vulgaridad inextirpables". 
En una entrevista concedida a Crónica de Concepción (20 de enero, 1958), Arteche añadió otras opiniones igualmente ilustrativas de su posición:

"Gabriela Mistral -dijo- es un caso aparte. Ella es una gran poetisa. Verdaderamente, aún la desconocemos. Los estudiosos han simplificado demasiado, no han llegado a la médula de su poesía. Esta sí que es una poesía hermética, profunda, llena de contenido. Y hay que considerar que los poetas del año 20 se reían de ella. Algunos surrealistas la llamaban la "viejita". ¡Ya quisieran escribir como ella!"

Interrogado sobre una opinión mía acerca de la crisis por que atraviesa la poesía chilena, Arteche declaró:

"De acuerdo, tomando la palabra crisis en su sentido de cambio de un estado a otro, pero no en el sentido de decadencia. Los poetas mayores han llevado indiscutiblemente a la poesía chilena a un callejón sin salida, pero ahora ese callejón ya está abierto, completamente abierto".

Humberto Díaz Casanueva respondió a Arteche en una intervención que por su trascendencia debiera ser incorporada a la publicación que se haga de los textos leídos en el Encuentro. En la imposibilidad de citar literalmente sus palabras debo referirme a las versiones que de ellas dieron los periódicos de Concepción. Según Crónica, Díaz Casanueva expresó:

"Los grandes poetas chilenos han sido gestores de un hecho extraordinario: han vigorizado el idioma castellano. Gabriela Mistral rompió con las cadenas del romanticismo; con ella el idioma adquirió algo duro, pétreo, dramático. La generación de 1920 sacudió las bases del idioma castellano. El idioma no es algo estático y rígido. No tenemos por qué respetarlo".

La Patria, en un comentario, dijo:

"Finalmente el poeta Díaz Casanueva, en representación de los poetas criticados, manifestó que su generación en que incluía a Juvencio Valle, Pablo Neruda y Pablo de Rokha, había adoptado el verso libre por su ímpetu renovador, no significando ello comodidad 
ni desconocimiento. Citó a Paul Valery, diciendo que "la poesía es eterna vacilación del sentido y del oído".

En una entrevista concedida a Crónica (21 de encro, 1958), Díaz Casanueva había dicho:

"Nadie ha hecho aún un análisis del aporte poético de la generación del año 20. Esto en gran parte se debe a los críticos oficiales, es decir, a los que vierten su opinión en diarios y revistas. La crítica debe ser esclarecedora. En cuanto al obscurantismo que se suele atribuir a algunos poetas, no creo que sea crítica valedera. Desde un punto de vista estético no hay poetas obscuros ni claros. La claridad y la obscuridad no son categorías estéticas".

En respuesta a la pregunta “¿Cuál es el mejor poeta de Chile?” declaró:

"Rosamel del Valle. Por lo menos es el más importante de la antigua generación de poetas. Es el que con mayor formalidad estudia la relación entre poesía e imagen. Tiene concepciones nuevas sobre imaginación, memoria, etc. Además, durante toda su vida ha actuado en poesía al margen de escuelas literarias o políticas. La poesía no sólo le interesa como medio de esparcimiento, sino como método de conocimiento".

"Creo - añadió en otro acápite- que la poesía lírica está en crisis. Algunos quieren darle más claridad, pero yo considero que hay que buscar nuevas formas de integración del movimiento lírico, como danza, ya que la poesía nació unida a la danza y a la música".

A propósito de esta última observación es necesario anotar que Díaz Casanueva insistió en establecer relaciones entre la poesía y otras esferas de la actividad intelectual. Su tema en el Encuentro fue: "Bases para una discusión sobre las relaciones actuales entre poesía y ciencia". He aquí una cita de este trabajo, que ayuda a comprender la concepción de la poesía que alienta Díaz Casanueva frente a la actitud crítica de Miguel Arteche:

"Tal vez corresponda al poeta, al margen de tendencias y programas, conforme a su creencia en las posibilidades y límites de la Poesía, posesionarse más intensamente de la nueva imagen del uni- 
verso y del hombre, vislumbrar las esperanzas, los riesgos y las necesidades del mundo actual, ahondar en la esencia de la Poesía, dilatar el campo de sus temas, problemas y métodos, exaltar facultades poéticas tales como la visión o la imaginación, participar mayormente en lo real a la vez que proseguir en la interiorización creciente y en la autoposesión de las fuerzas del hombre, anticipar si es posible uno de los dos futuros de que habla Spencer, y tener mayor conciencia de las potencialidades de la existencia actual y especialmente de la persona humana en el mundo cada vez más tecnificado en que vamos entrando" (El Sur, 22 de enero, 1958).

A estas dos posiciones, la de Arteche y la de Díaz Casanueva, es preciso agregar la de Nicanor Parra, quien, al revisar los comienzos literarios de la generación del 38, expuso con máxima nitidez los fundamentos de una poesía que representa una de las expresiones más importantes de la literatura chilena actual. Dijo Nicanor Parra: "Fundamentalmente, creo que teníamos razón al declararnos, tácitamente, al menos, paladines de la claridad y la naturalidad de los medios expresivos. Por lo menos en esa dirección se ha movido posteriormente el cuerpo de las ideas estéticas chilenas. ... El credo de la poesía diurna, como ahora me atrevo a llamarla, surgía, según nuestro exégeta (Tomás Lago) de poemas como "Hay un día feliz", "Es olvido", "Se canta al mar", y en él se fustigaba a los poetas nocturnos, es decir, a los poetas rebeldes de la Antología de Anguita. De más está decir que nosotros constituíamos el reverso de la medalla surrealista...

"Nosotros mismos tampoco podemos vanagloriarnos de haber ganado la batalla. El antipoema, que a la postre no es otra cosa que el poema tradicional enriquecido con la savia surrealista - surrealismo criollo o como queráis llamarlo-, debe aún ser resuelto desde el punto de vista psicológico y social del país y del continente a que pertenecemos, para que pueda ser considerado como un verdadero ideal poético. Falta demostrar que el hijo del matrimonio del día y de la noche celebrado en el ámbito del antipoema, no es una nueva forma de crepúsculo, sino un nuevo tipo de amanecer poético". 
En el fondo, la actitud de Parra y Arteche, así como el análisis autocrítico que realizaron novelistas y dramaturgos (Cf. los trabajos de José Manuel Vergara, Fernando Debesa y Luis A. Heiremans, y las intervenciones de Carlos León y J. R. Morales), indican una preocupación intensa con requerimiento de carácter ético y estético que, al no asumir una beligerancia sino en años recientes, pasaron inadvertidos para los escritores de 1920. Me parece que Díaz Casanueva reconoció este fenómeno y lo expuso claramente al decir que "mientras sus compañeros de generación se dedicaban a penetrar y divulgar la obra de los escritores que eran considerados maestros del oficio, como Kafka, Rilke, etc., estos jóvenes evocaban y hablaban de sus propios sueños, experiencias y realidades" (Cf. Las Noticias de Ultima Hora, 2 de febrero de 1958).

\section{4) La novela chilena actual}

La contraposición de dos épocas de la novela chilena se realizó de manera indirecta, como si hubiese existido un acuerdo tácito para enterrar las cenizas de un costumbrismo caduco en beneficio de dos tendencias cuyo desarrollo es y seguirá siendo simultáneo: la tendencia hacia un realismo popular de fuerte contenido político, y la tendencia hacia la universalidad sobre bases filosóficas, psicológicas y sociales. Nicomedes Guzmán pasó revista al realismo popular y, analizando sus antecedentes, expresó:

"Mariano Latorre vuelca todos los paisajes de nuestra tierra en el historial nutrido y variado de sus páginas; pero en su medio los hombres no se deleitan propiamente y se encuentran arañando en su propio corazón en prosecución de su destino. Luis Durand, Marta Brunet, Eduardo Barrios, Alberto Romero, Eugenio González, Carlos Sepúlveda Leyton, Juan Modesto Castro, demarcaron, a costa de esfuerzos, en lo que no hay que cansarse de insistir, la presencia del hombre de Chile, rudo y tierno, pendenciero y afable, luchador y vagabundo, y a su mujer y a sus chiquillos, y a sus perros, sus gallinas, su rancho o sus sucuchos que son parte de él mismo". 
Esta posición fue desarrollada también por Volodia Teitelboin, quien en su trabajo titulado "La generación del 40 y la búsqueda de la realidad chilena”, además de evocar con aguda percepción las circunstancias sociales y políticas de los años formativos de la actual generación literaria chilena, declaró refiriéndose en particular a la novela:

"Una literatura puramente nacional no existe, es un mito, pero más penoso es que no tenga nada propio o autóctono, porque entonces, esa literatura no existe. No creo que corresponda aquí hacer un catastro de la novela chilena. Pero sí decir algo en cuanto a su sentido. Me parece que ha desempeñado desde Blest Gana casi siempre un doble papel, divertir y reflejar la realidad. Generalmente nos ha reflejado tal como somos, sin revelar mucho de lo que nos gustaría ser. En los últimos tiempos la disciplina de la forma y de la estructura de la novela ha avanzado. Se ha demostrado ordinariamente nacional en sus personajes y escenarios, y contemporánea en cuanto trata problemas de su tiempo... Me parece que las nuevas generaciones de novelistas chilenos asimilan mejor que sus antecesores las conquistas de nuevas formas. Sin embargo, a mi juicio, casi siempre se adolece de falta de complejidad en la intriga. Creo que Blest Gana armaba mejor que los novelistas de hoy sus fantásticos enredos".

Presente a través de toda discusión acerca de la novela chilena estaba el propósito de no aceptar compromisos con la subliteratura del costumbrismo "pintoresquista". Las siguientes palabras de Guillermo Atías pueden considerarse sintomáticas de tal actitud:

“Tenemos una generación de escritores que eludieron sistemáticamente referirse a lo social y a la ciudad cuando más lo necesitábamos. Requerían su concurso para defenderse, para cautelar su fomación, pero ellos abandonaron el lugar, decidieron llevar su tienda literaria al campo. Allí entretejieron una farsa lírica que será necesario someter a revisión. Junto con dejar la ciudad vacía, los criollistas idearon una fábula campestre que no logra sostenerse, pero que ha lesionado el significado dinámico de la literatura, su función 
crítica. Habitaban la ciudad, eran ellos mismos personajes de su drama, pero prefirieron hablar del paisaje que habían entrevisto en sus paseos. La más desenfrenada actividad política ha tenido lugar entre nosotros en los últimos cien años, pero no contamos, que yo sepa, con un arquetipo del político fijado en la prosa; en cambio, tenemos al huaso, ese ente de una mitología privada, que, como tal, buscaríamos inútilmente en nuestro agro. Nada sabemos de la rica o abyecta vida de los partidos; la ficción no ha penetrado en la intimidad del funcionario aplastado por el tedio; casi desconocemos al obrero que, luchando con la miseria y las tinieblas, encuentra una luz y adopta una decisión".

La urgencia de llevar a la novela chilena a un plano de auténtica universalidad, proyectando sus personajes, sus ideas y sus temas hacia afuera, en búsqueda de un contacto con hombres que llevan el mismo trance de salvación o perdición quemando sus palabras, impone la necesidad de animarla con un dinamismo técnico de intachable alcurnia. Este ánimo de establecer un contacto universal en un plano de libre espiritualidad encontró expresión en el trabajo leído por José Manuel Vergara, trabajo que, no obstante ser rebatido por escritores de antagónicas tendencias, mostró fehacientemente el caso de un joven novelista en el acto, angustioso y complejo, de definir el sentido de su creación artística.

"Escribir novelas - dijo Vergara- es entonces para mí la manera de amar que tiene un novelista. $Y$ yo, como novelista, no me siento estéril ni habitante de una torre de marfil por el hecho de amar a mis personajes. Porque sé que si ellos son seres humanos en ellos estoy amando a la humanidad. $Y$ porque sé que un acto de amor, aùn el que un novelista efectúa en su obra, nunca será perdido, porque entrará a aumentar, en una gota más, el mar que la humanidad ha ido llenando día a día, sudorosamente, desde que el hombre mereció tal nombre".

En un plano estético puro Enrique Lafourcade insistió -y en sus palabras aludía a la creación literaria en general- en esta rela- 
ción de técnica, entendida como "forma", y "comprensión" o universalidad en el acto y resultado de la creación.

"Sin el conocimiento de una técnica expresiva - declaró-, sin esa canónica formal, el "objeto estético" queda inconcluso, a medio hacer. No alcanza a despegar del suelo. Echa un humo engañoso, sin poder ascensional alguno. La creación artística es, se hace, para los demás. Necesita ser entendida por ellos. Es, fundamentalmente, histórica... En esta época de cohetes el artista ha de tener viva en su conciencia la plenitud de su misión formal. Armar sus “objetos estéticos” al igual que los científicos arman sus Sputniks interplanetarios, para fines semejantes. Este vuelo hacia el entendimiento es el drama más hondo del auténtico creador".

Los resultados del Encuentro comenzarán a medirse en un plano inmediato de actividades universitarias y en un plano más intangible y complejo de significación estrictamente literaria. A este último plano no nos es dado referirnos por el momento. Los escritores de nuestra generación - según palabras de Teitelboin- comenzamos a trabajar "contra el tiempo". Sería prematuro juzgar la obra de una generación en el instante más arduo de su proceso creativo. En el plano de las relaciones del escritor con la Universidad, en cambio, el Encuentro asume una importancia de indiscutible actualidad. Por primera vez en Chile los escritores se han servido de la tribuna universitaria para exponer ante el público su testimonio personal acerca de los problemas que atañen a su labor creadora y de las relaciones que ellos guardan con la vida social del país. En un ambiente de amplia libertad, que es un orgullo para la democracia chilena, se esgrimieron argumentos políticos, filosóficos, religiosos, de la más diversa índole. Todos los escritores fueron escuchados respetuosamente por un público heterogéneo que no se limitó a seguir en silencio los debates, sino que, en ocasiones, participó en ellos y expresó, 
además, su entusiasmo en cartas dirigidas a los periódicos de Concepción.

De la acción concertada de los escritores participantes en el Encuentro y del Rector de la Universidad de Concepción, don David Stitchkin Branover, cuya inspiración, dinamismo y visión progresista de la vida intelectual del país le señalaron desde el comienzo de nuestra reunión como a un auténtico líder; de sus colaboradores, el doctor Hugo Trucco, el poeta Gonzalo Rojas, originador y presidente del Encuentro, y los profesores Alfredo Lefebvre y Juan Loveluck, surgirán realizaciones de valor práctico inmediato: desde luego, la creación de una editorial universitaria destinada primordialmente a dar a conocer las obras de los escritores de las nuevas generaciones; la celebración periódica de nuevos Encuentros, no sólo en Concepción sino a través del país; la fundación de seminarios de creación literaria destinados especialmente a orientar a los escritores jóvenes; y la iniciación de una segunda época de Atenea, la prestigiosa tribuna de la intelectualidad chilena que dirige desde Santiago Milton Rossel, para hacer coincidir la publicación de los trabajos leídos en el Encuentro con la aparición del primer número de la revista editado directamente en las prensas de la Universidad de Concepción. 